\title{
STUDY OF RISK FACTORS, CLINICAL PROFILES AND ANGIOGRAPHIC PATTERNS IN PATIENTS OF CORONARY ARTERY DISEASE IN A TERTIARY CARE CENTRE IN KOLKATA
}

KEY WORDS:

\section{Saroj Mandal*}

\section{Vignesh.R}

\section{Sidnath Singh}

MD(MED), DM(CARDIO), FRCP(GLAS), FACC(USA), FSCAI(USA), FESC(USA), FESC(EURO), Assosciate Professor,Department of Cardiology,IPGMER \& SSKM Hospital,Kolkata. *Corresponding Author

MD(MED, DM(CARDIO PDT), Department of Cardiology,IPGMER \&SSKM Hospital,Kolkata.

MD(MED)DM(CARDIO)PDT, Department of Cardiology,IPGMER \&SSKM Hospital,Kolkata.

BACKGROUND:Coronary artery disease (CAD) is one of the most common causes of mortality and morbidity in both developed and developing countries. It is a leading cause of death in India, and its contribution to mortality is rising. Considering the increasing burden of coronary artery disease and its mortality and the usefulness of identifying risk factors, studying the clinical profile and angiographic pattern will help us intervene the disease at various levels which can help control the morbidity and mortality of coronary artery diease.

MATERIALS AND METHOD: The present study was conducted in the Department of Cardiology,IPGMER \& SSKM Hospital,Kolkata during the period of January 2019 to December 2019.This is a hospital based observational prospective study with prospective data collection,where all patients of coronary artery disease who had undergone coronary angiography has been taken into consideration to find out the risk factors, clinical profiles and angiographic patterns in coronary artery disease patients in Kolkata.

RESULTS: Maximum patients were present in the age group 51-60 years of age. Mean age is 56.7+11.6sd.Male patients were $70 \%$ and female patients were $30 \%$.Most common symptom was chest pain, $90 \%$ of patients had it during the time of presentation. The next frequent symptom was shortness of breath which was seen in $52 \%$ of patients. Most common risk factor was smoking which was seen in 58\% of patients. Next frequent risk factor being hypertension seen in $43.5 \%$ of patients. Obesity was seen in $59.2 \%$ of patients. On coronary angiography, $40 \%$ of patients had Single vessel CAD, $27.3 \%$ had double vessel CAD,23.5\% had Double vessel CAD,6.5\% had Non-Significant CAD and $2.7 \%$ had Normal coronaries(recanalized epicardial coronaries).LAD was involved in 73.5\% of patients, $51.7 \%$ had RCA involved,43.5 \% had LCX involved and LMCA was involved in $1.7 \%$ of patients.

CONCLUSION:Smoking and hypertension are the most common risk factors. Single vessel disease is the most common angiographic pattern.Risk factors should be addressed properly to decrease the morbidity and mortality of coronary artery disease.

\section{INTRODUCTION:}

Coronary artery disease (CAD) is leading cause of mortality worldwide ${ }^{[1]}$ and by the year 2020 , will be first in the leading causes of disability ${ }^{[2]}$

In the last three decades, the prevalence of CAD has increased from $1.1 \%$ to about $7.5 \%$ in the urban population and from $2.1 \%$ to $3.7 \%$ in the rural population. ${ }^{[3]}$

Risk factors generally apply to a variable that can predict a future cardiovascular event, but some of these predictors are also potential targets for interventions. The past 50 years have witnessed great progress in identifying a number of life style, as well as biochemical and genetic, factors associated with coronary heart disease and in disseminating this information to the public. ${ }^{[4]}$

The identification of major risk factors and their effective control through population based strategies of prevention can reduce the incidence of coronary artery disease. The rise and subsequent decline in coronary artery disease epidemic in almost all industrialized country in the later half of twentieth century has been well documented ${ }^{[5]}$

Several risk factors contribute to the increase in the prevalence of CAD in different age groups. The traditional risk factors such as hypertension (HT), diabetes mellitus (DM), high levels of triglycerides (TGs), high levels of lowdensity lipoprotein cholesterol (LDL-C) and low levels of high-density lipoprotein cholesterol (HDL-C), stressful, and sedentary lifestyle changes are suggested as additional risk factors for $\mathrm{CAD} .^{[6]}$

Significant differences in the prevalence of coronary artery disease exist with respect to gender, age and ethnicity. Cardiovascular diseases have emerged as a major health burden in developing countries. ${ }^{[7]}$

\section{MATERIALS AND METHODS:}

This Observational prospective study was carried out at the Department of Cardiology, Institute of Post Graduate Medical Education and Research,Kolkata.

The purpose of the study was to investigate the demographic, clinical characteristics, angiographic findings and risk factors of 510 patients from January 2019 to December 2019. Inclusion criteria are patients admitted for STEMI, NSTEMI, or UA and those who underwent coronary angiography. Patients having prior cardiac conditions that could affect outcome like valvular heart disease, cardiomyopathy, and previous left bundle branch block were excluded. Patients with diagnosed acute or chronic liver disease, renal impairment or having secondary conditions that could precipitate angina (anemia, arrhythmias, fever) were also excluded from the study. Coronary artery disease was diagnosed on the basis of clinical and non invasive evaluation. Elective coronary angiography was done in patients having prior myocardial infarction, unstable angina and stable angina with positive stress ECG or prior to surgical treatment of valvular and adult congenital heart disease.

Baseline demographic, clinical, risk factors were collected. Selective coronary angiogram was done using standard technique within 48 hour of admission unless patient is hemodynamically unstable or with deranged renal parameters. Atherosclerotic coronary artery disease was defined as $\geq 1$ epicardial coronary segment with stenosis $\geq 25 \%$ and was diagnosed visually. 
PARIPEX - INDIAN JOURNAL OF RESEARCH | Volume - $10 \mid$ Issue - 09 |September - 2021 | PRINT ISSN No. 2250 - 1991 | DOI : $10.36106 /$ paripex

Normal vessels were defined as the complete absence of any disease in the left main coronary artery (LMCA), left anterior descending (LAD), right coronary artery ( $R C A)$, and left circumflex (LCX) as well as in their main branches (diagonal, obtuse marginal, ramus intermedius, posterior descending artery, and posterolateral branch). Patients were classified as having single-vessel disease (SVD), double-vessel disease (DVD) or triple vessel disease (TVD) accordingly.

\section{RESULTS:}

AGE AND SEX DISTRIBUTION OF PATIENTS:

Tablel:

\begin{tabular}{|l|l|l|}
\hline Age Group & Frequency & Percentage \\
\hline$\leq 30$ & 14 & 2.6 \\
\hline $31-40$ & 33 & 6.4 \\
\hline $41-50$ & 88 & 17.2 \\
\hline $51-60$ & 204 & 40 \\
\hline $61-70$ & 141 & 28 \\
\hline$>70$ & 30 & 5.8 \\
\hline Total & 510 & 100 \\
\hline
\end{tabular}

\section{Table2:}

\begin{tabular}{|l|l|l|}
\hline Gender & Frequency & Percentage \\
\hline Male & 357 & 70 \\
\hline Female & 153 & 30 \\
\hline Total & 510 & 100 \\
\hline
\end{tabular}

Age Distribution

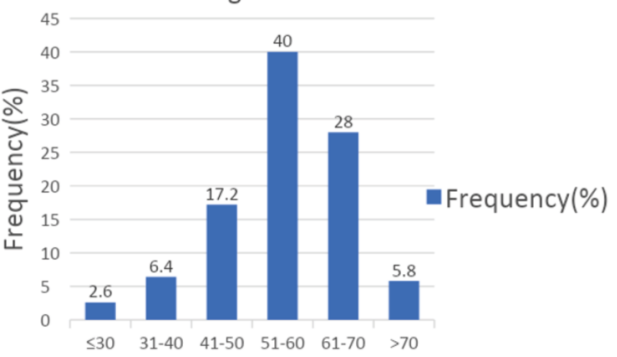

Age (Years)

Table3:

\begin{tabular}{|c|c|c|c|c|}
\hline \multirow[t]{2}{*}{ AGE(YEARS) } & & \multicolumn{2}{|c|}{ GENDER } & \multirow[t]{2}{*}{ TOTAL } \\
\hline & & MALE & FEMALE & \\
\hline \multirow[t]{2}{*}{$\leq 30$} & No. & 9 & 5 & 14 \\
\hline & $\%$ & $1.7 \%$ & $0.9 \%$ & $2.6 \%$ \\
\hline \multirow[t]{2}{*}{$31-40$} & No. & 28 & 5 & 33 \\
\hline & $\%$ & $5.5 \%$ & $0.9 \%$ & $6.4 \%$ \\
\hline \multirow[t]{2}{*}{$41-50$} & No. & 65 & 23 & 88 \\
\hline & $\%$ & $12.7 \%$ & $4.5 \%$ & $17.2 \%$ \\
\hline \multirow[t]{2}{*}{$51-60$} & No. & 143 & 61 & 204 \\
\hline & $\%$ & $28 \%$ & $12 \%$ & $40 \%$ \\
\hline \multirow[t]{2}{*}{$61-70$} & No. & 97 & 44 & 141 \\
\hline & $\%$ & $19 \%$ & $9 \%$ & $28 \%$ \\
\hline \multirow[t]{2}{*}{$>70$} & No. & 15 & 15 & 30 \\
\hline & $\%$ & $2.9 \%$ & $2.9 \%$ & $5.8 \%$ \\
\hline \multirow[t]{2}{*}{ TOTAL } & No. & 357 & 151 & 510 \\
\hline & $\%$ & $70 \%$ & $30 \%$ & $100 \%$ \\
\hline
\end{tabular}

Sex Distribution

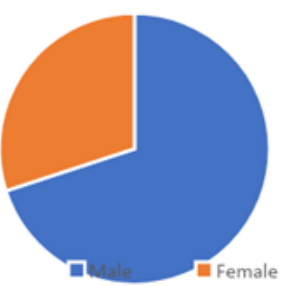

AGE AND SEX DISTRIBUTION:

DISTRIBUTION OF MAJOR CLINICAL SYMPTOMS
Table4:

\begin{tabular}{|l|l|l|}
\hline CHARACTERISTICS & FREQUENCY & PERCENTAGE \\
\hline Chest Pain & 459 & 90 \\
\hline Shortness of Breath & 265 & 52 \\
\hline Orthopnoea & 10 & 1.9 \\
\hline $\begin{array}{l}\text { Paroxysmal Nocturnal } \\
\text { Dyspnoea }\end{array}$ & 10 & 1.9 \\
\hline Palpitation & 102 & 20 \\
\hline Syncope & 51 & 10 \\
\hline Sweating & 204 & 40 \\
\hline Angina equivalents & 112 & 22 \\
\hline
\end{tabular}

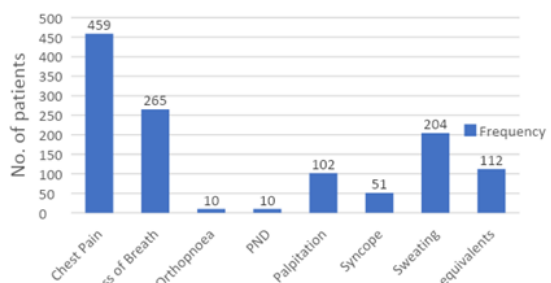

DISTRIBUTION OF RISK FACTORS OF CORONARY ARTERY DISEASE:

Table5:

\begin{tabular}{|l|l|l|}
\hline RISK FACTORS & FREQUENCY & PERCENTAGE \\
\hline Diabetes & 157 & 30.7 \\
\hline Hypertension & 222 & 43.5 \\
\hline Smoking & 296 & 58 \\
\hline Dyslipidemia & 69 & 13.5 \\
\hline Family H/o CAD & 46 & 9 \\
\hline Previous MI & 55 & 10.8 \\
\hline Tobacco & 93 & 18.2 \\
\hline Alcohol & 139 & 27.2 \\
\hline Sedentary Lifestyle & 185 & 36.2 \\
\hline
\end{tabular}

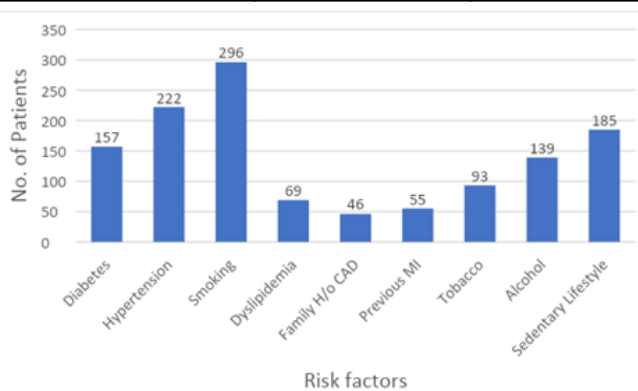

DISTRIBUTION OF CLINICAL SIGNS:

Table6:

\begin{tabular}{|l|l|l|}
\hline RISK FACTORS & FREQUENCY & PERCENTAGE \\
\hline Pallor & 37 & 7.3 \\
\hline Icterus & 0 & 0 \\
\hline Cyanosis & 0 & 0 \\
\hline Clubbing & 0 & 0 \\
\hline Oedema & 37 & 7.3 \\
\hline Jugular Venous Pulse & 40 & 7.8 \\
\hline
\end{tabular}

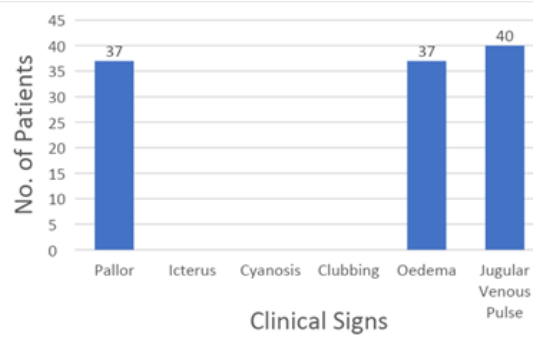

BMI IN PATIENTS: 


Table7:
\begin{tabular}{|l|l|l|l|}
\hline BMI & CATEGORY & FREQUENCY & PERCENTAGE \\
\hline$<18.5$ & Underweight & 0 & 0 \\
\hline $18.5-22.9$ & Normal & 115 & 22.6 \\
\hline $23-24.9$ & Overweight & 93 & 18.2 \\
\hline$>25$ & Obese & 302 & 59.2 \\
\hline TOTAL & & 510 & 100 \\
\hline
\end{tabular}

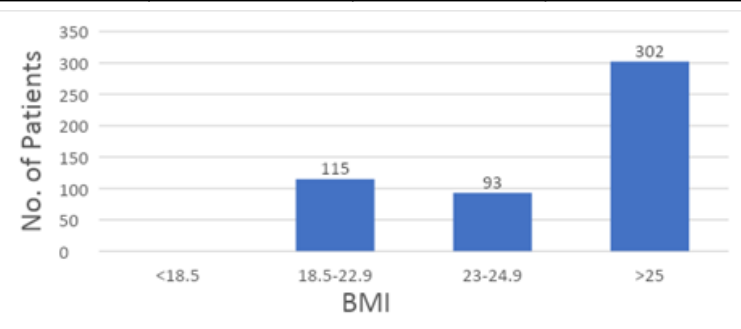

\section{ANGIOGRAPHIC FINDINGS IN PATIENTS:}

Table8:

\begin{tabular}{|l|l|l|}
\hline PATTERN & FREQUENCY & PERCENTAGE \\
\hline Normal coronaries & 14 & 2.7 \\
\hline Non-significant CAD & 33 & 6.5 \\
\hline Single Vessel CAD & 204 & 40 \\
\hline Double Vessel CAD & 120 & 23.5 \\
\hline Triple Vessel CAD & 139 & 27.3 \\
\hline Total & 510 & 100 \\
\hline
\end{tabular}

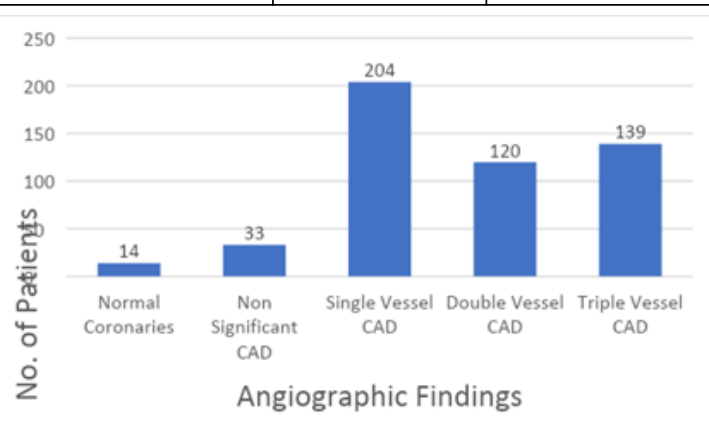

\section{PATTERN OFVESSELS INVOLVED:}

Table9:

\begin{tabular}{|l|l|l|}
\hline Vessel involved & No. of patients & Percentage \\
\hline LMCA & 9 & 1.7 \\
\hline LAD & 375 & 73.5 \\
\hline LCX & 222 & 43.5 \\
\hline RCA & 264 & 51.7 \\
\hline
\end{tabular}

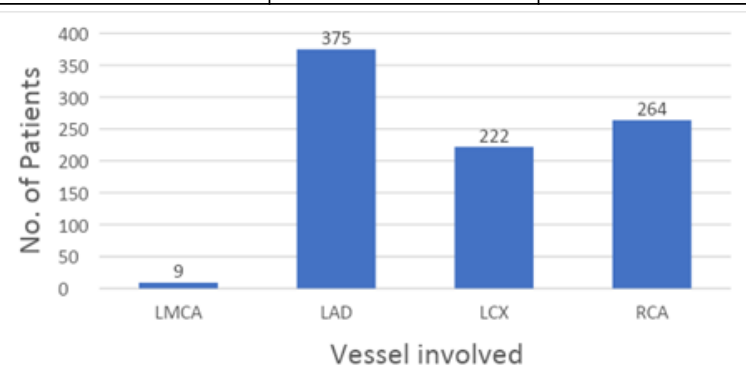

RESULTS AND DISCUSSION:

Age and Sex wise Analysis of patients with CAD:

In our study Maximum patients were in age group 51-60 years consisting $40 \%$ of patients, and $28 \%$ were in age group $61-70$ years , $17.2 \%$ were in age group $41-50$ years, $6.4 \%$ patients were in age group $31-40$ years, $5.8 \%$ patients were in age group $>70$ years and $2.6 \%$ patients were in age group $\leq 30$ years.

Maximum were male patients i.e. 357(70\%) of patients and |www.worldwidejournals.com
$153(30 \%)$ were female patients.In all the age groups males were more than females except in age group $>70$ years equal number of males and females affected. In our study mean age is $56.7+11.6 \mathrm{sd}$.

Rajni Sharma et al,study at Sri Jayadeva Institute of Cardiovascular Sciences and Research, Bengaluru, Karnataka, India studied Clinical Characteristics, Angiographic Profile and in Hospital Mortality in Acute Coronary Syndrome Patients in South Indian Population. Among 1562 ACS patients majority were male 1242 (79.5\%) and $320(20.5 \%)$ were female. The mean age of presentation for male was $53.28 \pm 11.54 .^{[8]}$

In our study, the mean age of presentation was $56.70 \pm 11.6$ years comparable to other studies done in India, that is, CREATE registry ( $56 \pm 13$ years) and Jose and Gupta study (57 \pm 12 years) $52 \pm 10.8$ years in a study reported by Maqbool Jafary et $\mathrm{al}^{[0]}$ and $58 \pm 1$ lyears by Sahed et $\mathrm{al}^{[10]}$ in Pakistan but lower than the western population as in COURAGE trial $62 \pm 5$ years conducted in USA, study by Hochman et al ${ }^{[11]}$ (69 years), and Chang et al. (73 years). ${ }^{[12]}$

MAK Akanda et al,study at at National Institute of Cardiovascular Disease (NICVD), Dhaka studied Demographic Profile, Clinical Presentation \& Angiographic Findings in 637 Patients with Coronary Heart Disease. Among 637 patients, $547(85.9 \%)$ were male and $90(14.1 \%)$ were female. All of them were between 22 to 76 years of age with mean age $50.15 \pm 8.8 .^{[13]}$

Bajarang Lal Bansal et al,study at department of medicine, Dr.B.R.A.M Hospital studied Risk factors, clinical profiles and angiographic patterns in patients of coronary artery disease in a tertiary care centre.Maximum patients were in age group 41-50 years. Male patients were $79.4 \%$ and female were $20.58 \%$.Mean age was 55years +12.11 sd. ${ }^{[14]}$

So as per all these studies males are affected more than females.

\section{ANALYSIS OF CLINICAL SYMPTOM IN PATIENTS:}

Most common symptom in our study was Chest pain, 459 $(90 \%)$ patients had it at he time of presentation, followed by shortness of breath which was present in $265(52 \%)$ patients, $204(40 \%)$ had sweating, $112(22 \%)$ had angina equivalent, 102 (20\%) had palpitation, $51(10 \%)$ had syncope, $10(1.9 \%)$ had Orthopnoea and $10(1.9 \%)$ had Paroxysmal Nocturnal Dyspnoea.

Bajarang Lal Bansal et al,study at department of medicine, Dr.B.R.A.M Hospital studied Risk factors,clinical profiles and angiographic patterns in patients of coronary artery disease in a tertiary care centre.in this study Most common symptom was chest pain(84 out of 110 patients) followed by breathlessness ( 55 out of 110 patients). ${ }^{[14]}$

Our study correlates with the above study in terms of clinical symptom.

\section{ANALYSIS OF CLINICAL SIGNS ON GENERAL PHYSICAI EXAMINATION:}

In our study Raised JVP was seen in 40(7.8\%) patients ,pallor in $37(7.3 \%)$ patients and oedema in $37(7.3 \%)$ patients.

\section{ANALYSIS OF RISK FACTORS IN PATIENTS:}

In our study Smoking was the most common risk factor which was present in 296(58\%) of patients followed by Hypertension in 222(43.5\%) of patients.Sedentary life style was seen in 185(36.2\%) of patients,Diabetes in 157(30.7\%)of patients,Alcohol intake in 139(27.2\%) of patients,Tobacco in $93(18.2 \%)$ of patients,Dyslipidemia in $69(13.5 \%)$ of patients,Previous MI in 55(10.8\%) of patients and Family history of CAD in $46(9 \%)$ of patients. 
In our study $302(59.2 \%)$ had Obesity defined by $\mathrm{BMI}>25$. $93(18.2 \%)$ patients were overweight with BMI between 23 and 24.9.

Rajni Sharma et al,study at Sri Jayadeva Institute of Cardiovascular Sciences and Research, Bengaluru, Karnataka, India studied Clinical Characteristics, Angiographic Profile and in Hospital Mortality in Acute Coronary Syndrome Patients in South Indian Population. A total of 578/1562 (37\%) patients were diabetic and 628/1562 $(40.2 \%)$ patients were hypertensive. Smoking was most prevalent risk factor seen in $770 / 1562$ (49.30\%) patients. Active smoking in our study was noticed only in male, that is, $770(62 \%)$ of total male (1242) patients. Women were rather tobacco chewers. Dyslipidemia was present in 593/1562 (37.96\%) patients. Obesity in 463/1562 (29.64\%) patients and family history of CAD was significant in 152/1562 (9.73\%) patients. ${ }^{[8]}$

Arumugam C et al study,at Department of Cardiology, Chettinad Hospital and Research Institute, Chennai studied pattern of coronary artery disease in young south Indian population. Hypertension was the most prevalent risk factor $(14.8 \%)$ followed by diabetes $(10.5 \%)$, smoking $(2.8 \%)$ and dyslipidemia $(2.4 \%) .{ }^{[15]}$

MAK Akanda et al,study at National Institute of Cardiovascular Disease (NICVD), Dhaka studied Demographic Profile, Clinical Presentation \& Angiographic Findings in 637 Patients with Coronary Heart Disease. Most prevalent risk factors were smoking $(60 \%)$ and dyslipidaemia $(60 \%)$. Thirty five percent patients were hypertensive and $10 \%$ patient had diabetes. ${ }^{[13]}$

Singh Lakhan et al at Department of Medicine, Chhattisgarh Institute of Medical Sciences, Bilaspur, India, studied Risk Factor Profile for Coronary Artery Disease Among Young \& Elderly Patients in Chhattisgarh. The hypertension (20\%), smoking (22\%), diabetes mellitus( $11 \%)$ and dyslipidemia $(8 \%)$ were the commonest risk factors in young patients . Overall risk factors were more likely in males compared to females. Regarding elderly patients, Diabetes Mellitus (21\%), hypertension (14\%) smoker (17\%), kidney disease $(11 \%)$ and dyslipidemia (9\%) were the commonest risk factors. ${ }^{[16]}$

Lalatendu Swain et al study,at Government Medical College and Hospital, Balasore, Odisha, India studied Demographic and clinic-angiographic profile of coronary artery disease in young adults: a retrospective observational study. smoking as a single most common risk factor seen in 98 (65.3\%) cases. Other risk factor observed are hypertension in 40 (26.7\%), diabetes in 23 (15.3), dyslipidemia in 14 (9.3), family history of $\mathrm{CAD}$ in $13(8.7 \%)$ and obesity in $8(5.3 \%)$ cases $^{[17]}$ Our study correlates with most of the study where smoking and hypertension are more commonly associated with CAD.

\section{ANALYSIS OF ANGIOGRAPHIC FINDINGS:}

In our study Single vessel CAD was present in 204(40\%) patients followed by $139(27.3 \%)$ patients had Triple vessel CAD, 120(23\%) patients had Double vessel disease,33(6.5\%) had Non significant CAD,14(2.7\%) had normal coronaries (recanalized epicardial coronaries).

In our study 375(73.5\%) patients had LAD involved, 264 (51. $7 \%$ ) had RCA involved,222(43.5\%) patients had LCX involved and $9(1.7 \%)$ patients had LMCA involved.

Lalatendu Swain et al study,at Government Medical College and Hospital, Balasore, Odisha, India studied Demographic and clinic-angiographic profile of coronary artery disease in young adults: a retrospective observational study. Among 150 cases with critical CAD, SVD was most prevalent seen in 103 $(68.7 \%)$ cases, followed by DVD in $34(22.6 \%)$ and TVD in 13 $(8.7 \%)$ cases. Among the single vessel disease cases, location of stenosis was seen in LAD in $62(41.3 \%)$, LCX in 15 (10\%), $\mathrm{RCA}$ in $23(15.3 \%)$ and left main coronary artery in $3(2 \%)$ cases. ${ }^{[17]}$

Sunita Dinkar Kumbhalkar et al study, at Government Medical College and Superspeciality Hospital, Nagpur studied Clinical and Angiographic Profile of Young Patients with Ischemic Heart Disease: A Central India Study. The study showed SVD in $57.1 \%$ of the cases followed by DVD (11.5\%) and TVD $(7.1 \%)$. No patient had LMCA involvement in our study. In patients with SVD, LAD was predominantly involved $(82.5 \%)$ followed by RCA $(12.5 \%)$ and LCX $(5 \%) .{ }^{[18]}$

Khadkikar GD et al, observed SVD, DVD, TVD and no vessel disease in $50 \%, 13.6 \%, 4.5 \%$ and $31.8 \%$ of cases respectively. ${ }^{[19]}$

Saghir $\mathrm{T}$ et al, had also observed SVD as the most common type of CAD in patients $<40 \mathrm{yr}$ age in $39 \%$ cases followed by DVD in 20\%, TVD in $12 \%$ and left main coronary artery in $2 \%$ of cases. $\mathrm{LAD}$ as the most common artery involvement in obstructive type of CAD in patients $<40 \mathrm{yr}$ age, seen in $47 \%$ of RCA in $43 \%$ and LCX in $10 \%$ cases. $^{[20]}$

Colkesen $\mathrm{AY}$ et al, in their study on coronary artery disease in young adults under 35 years of age also found $L A D$ was the most commonly involved vessel, followed by RCA, LCX, and LMCA. ${ }^{[21]}$

Cole et al, in their long-term follow up of coronary artery disease presenting in young adults identified single vessel disease as the most common type seen in $58 \%$ of CAD patients below 40 years of age. ${ }^{[22]}$

Yusuf S et al, had also found LAD as the most common vessel involved (60), followed by RCA (52), left circumflex (41), and left main. ${ }^{[23]}$

Sricharan KN et al, in another study from South India observed majority of the patients $(57.14 \%)$ had SVD, followed by normal coronaries $(22.45 \%) ; 16.3 \%$ had DVD and $4 \%$ had multivessel disease. ${ }^{[24]}$ Badran $\mathrm{HM}$ et al, had also identified more incidence of SVD (66\%) than DVD (21\%) and TVD (9\%) and no vessel disease in $4 \%$ of cases in their study on $<45 \mathrm{yr}$ age group patients. They observed involvement of LAD in maximum number of cases (71\%), followed by RCA (24\%), LCX $(13 \%)$ and left main (1\%) of cases. ${ }^{[25]}$

Christus T et al, studied higher percentage of SVD (32.5\%) than DVD (19\%) and TVD (12.5\%) and left main coronary artery in $1.5 \%$ of cases. ${ }^{[26]}$

Our study correlates with most of the studies where single vessel CAD is the most common angiographic pattern and $\mathrm{LAD}$ is the most common vessel involved.

\section{SUIMIMARY AND CONCLUSION:}

1. Maximum patients were present in the age group 51-60 years of age.Mean age is $56.7+11.6 \mathrm{sd}$.

2. Male patients were $70 \%$ and female patients were $30 \%$.

3. Most common symptom was chest pain, $90 \%$ of patients had it during the time of presentation.The next frequent symptom was shortness of breath which was seen in $52 \%$ of patients.

4. Most common risk factor was smoking which was seen in $58 \%$ of patients.Next frequent risk factor being hypertension seen in $43.5 \%$ of patients.

5. Obesity was seen in $59.2 \%$ of patients.

6. On coronary angiography, $40 \%$ of patients had Single vessel $\mathrm{CAD}, 27.3 \%$ had double vessel $\mathrm{CAD}, 23.5 \%$ had Double vessel CAD, $6.5 \%$ had Non-Significant CAD and $2.7 \%$ had Normal coronaries(recanalized epicardial coronaries).

7. LAD was involved in $73.5 \%$ of patients, $51.7 \%$ had RCA 
involved,43.5 \% had LCX involved and LMCA was involved in $1.7 \%$ of patients.

\section{REFERENCES:}

1. American Heart Association / American Stroke Asssociation statistical data on highlights of acute coronary syndrome, 2005.

2. Murray CJ, Lopez AD. Mortality by cause for eight regions of the world: Global Burden of Disease Study.Lancet 1997;349:1269-76.

3. Chadha SL, Radhakrishnan S, Ramachandran K, Kaul U, Gopinath N. Epidemiological study of coronary heart disease in urban population of Delhi.Indian J Med Res 1990;92:424-30.

4. Gaziano MJ, Manson JE, Ridker PM. Primary and secondary prevention of coronary heart disease. In : Libby P, Bonow RO. Mann DL , Zipes DP, editors. Braunwalds Heart disease. A text book of cardiovascular medicine. 8th ed. Saunders:Philadelphia;2008.P. 1119-48.

5. Maskey A, Sayami A, Pamdey MR: coronary artery dieseae: An emerging epidemic in Nepal.J.Nepal Med Association 2003; 42:122-124.

6. 5. Gupta R. Epidemiological evolution and rise of coronary heart disease in India. South Asian J Prev Cardiol 1997;1:14-20.

7. Reddy KS, Yusuf S. Emerging epidemic of cardiovascular disease in developing countries. Circulation 1998;97:596-601.

8. Rajni Sharma, Shivkumar Bhairappa, SR Prasadl, Cholenahally Nanjappa Manjunath . Sri Jayadeva Institute of Cardiovascular Sciences and Research, Bengaluru, Karnataka, India studied Clinical Characteristics, Angiographic Profile and in Hospital Mortality in Acute Coronary Syndrome Patients in South Indian Population.www.heartindia.net

9. Reddy KS, Yusuf S. Emerging epidemic of cardiovascular disease in developing countries. Circulation 1998;97:596-601.

10. Fourneer JA, Sanchez A, Quero J, Fernandez-Cortacero JAP, Gonzalez BA. Myocardial infarction in men aged 40 years or less: a prospective clinical angiographic study. Clin cardiol. 1996; 19:631-6

11. Hochman JS, Tamis JE, Thompson TD, Weaver WD, White HD, Van de Werf F, et al. Sex, clinical presentation, and outcome in patients with acute coronary syndromes. Global Use of Strategies to Open Occluded Coronary Arteries in Acute Coronary Syndromes IIb Investigators. N Engl J Med 1999;341:226-32.

12. Chang WC, Kaul P, Westerhout CM, Graham MM, Fu Y, Chowdhury T, et al. Impact of sex on long-term mortality from acute myocardial infarction vs unstable angina. Arch Intern Med 2003;163:2476-84

13. MAK Akandal, SY Ali2, AEMM Islam3, MM Rahman4, A Parveen5, MK Kabir6, L Begum7, RC Barman8. Demographic Profile, Clinical Presentation \& Angiographic Findings in 637 Patients with Coronary Heart Disease. Faridpur Med.Coll.J.2011;6(2):82-85

14. Bajarang Lal Bansal,Akshata P.J et al,study at department of medicine, Dr.B.R.A.M Hospital studied Risk factors,clinical profiles and angiographic patterns in patients of coronary artery disease in a tertiary care centre, Chattisgarh,Evolution Med.Dent,Sci.2016;5(104):7638-7648

15. Arumugam Cl, Chokkalingam Ml, Ganesh N1, Pradeep G Nayarl, Ahamed basha A2, Nawaz Ahmed S K3. A study of pattern of coronary artery disease in young south Indian population. Indian Journal of Basic and Applied Medical Research;June 2016:Vol.-5, Issue-3,P.216-224.

16. Singh LAkhanl, Jain Lalit1 , Singh Hemlata2, Nigam Prashant*3. Risk Factor Profile for Coronary Artery Disease Among Young \& Elderly Patients in Chhattisgarh.J Clin Biomed Sci 2013;3(4):171-76

17. Lalatendu Swain 1*, Prabhat Nalini Routray2, Demographic and clinicangiographic profile of coronary artery disease in young adults: a retrospective observational study, International Journal of Research in Medical Sciences Swain L et al. Int J Res Med Sci.2018 Jul;6(7):2264-2270

18. Sunita Dinkar Kumbhalkarl; Vikas V Bisne2. Clinical and Angiographic Profile of Young Patients with Ischemic Heart Disease: A Central India Study. Journal of Clinical and Preventive Cardiology | Volume 8 ; Issue 1 i JanuaryMarch 2019

19. Khadkikar GD, Mangudkar SS, Landge JA. Comparison of conventional risk factors, clinical and angiographic profile between younger and older coronary heart disease patients. Inter J Res Med Sci. 2016 Dec 25;4(2):567-70

20. Saghir T, Qamar N, Sial J. Coronary angiographic characteristics of coronary artery disease in young adults under age forty years compare to those over age forty. Pakistan Heart Journal. 2008;41(3)

21. Colkesen AY, Acil T, Demircan S, Sezgin AT, Muderrisoglu H. Coronary lesion type, location, and characteristics of acute ST elevation myocardial infarction in young adults under 35 years of age. Coronary artery disease. 2008 Aug $1 ; 19(5): 345-7$.

22. Cole JH, Miller III JI, Sperling LS, Weintraub WS. Long-term follow-up of coronary artery disease presenting in young adults. J American College Cardiology.2003 Feb 19;41(4):521-8.

23. Yusuf S, Hawken S, Ounpuu S, Dans T, Avezum A, Lanas F, et al. Effect of potentially modifiable risk factors associated with myocardial infarction in 52 countries (the INTERHEART study): Case-control study. Lancet. 2004; 364: 937-52

24. Sricharan KN, Rajesh S, Rashmi K, Meghana HC, Badiger S, Mathew S. Study of acute myocardial infarction in young adults: Risk factors, presentation and angiographic findings.J Clin Diagn Res. 2012;6:257-60

25. Badran HM, Elnoamany MF, Khalil TS, Eldin MM. Age-related alteration of risk profile, inflammatory response, and angiographic findings in patients with acute coronary syndrome. Clin Med Cardiol. 2009;3:15-28

26. Christus T, Shukkur AM, Rashdan I, Koshy T, Alanbaei M, Zubaid M, et al. Coronary artery disease in patients aged 35 or less-A different beast? Heart Views. 2011;12:7-11. 